\title{
Large Cell Carcinoma Mimicking Non Resolving Pneumonia
}

\author{
MOHAMMAD ASHI KI MRAN KHAN, ${ }^{1}$ MD. TITU MI AH, ${ }^{2}$ MD. SHAHRI AR MAHBUB, ${ }^{3}$ RATAN DAS GUPTA, ${ }^{2}$ HAM \\ NAZMUL AHASAN, ${ }^{4}$ MD. MUNAWWAR ALAMGI R KHAN, ${ }^{1}$ SHAMSUL AREFIN PATWARY, ${ }^{5}$ \\ HOMAYRA TAHSEEN HOSSAI ${ }^{6}$
}

\begin{abstract}
:
Fever, chest pain, cough in a young lady usually does not ring any alarm bell. We present here a case of a young lady who had typical symptoms of community acquired pneumonia who initially responded to regular antibiotics but later was investigated to have large cell carcinoma. Presentation of lung cancer as non-resolving pneumonia is not a very common phenomenon and diagnosis can present a diagnostic challenge to the clinician.
\end{abstract}

Keyword: Non-resolving pneumonia, Young lady, Chest pain, fever, Large cell Carcinoma, Bangladesh.

\section{Introduction:}

Worldwide, lung cancer is one of the most common types of neoplasia and surpasses all others in terms of mortality rates. ${ }^{1,2}$ Over the past 20 years, there has been an increase in incidence of lung cancer in women where it has increased by about $134 \%$, making it the second leading cause of death from cancer among females, whereas it has increased by only $57 \%$ in men. ${ }^{3}$ The literature projects that, in the next two decades, lung cancer will be the neoplasia with the highest mortality rate among women in countries where women will take the habit of smoking. ${ }^{4}$ But presentation of lung cancer in the form of non-resolving pneumonia is rather an atypical one and high index of suspicion is required for its diagnosis, specially in the young. While considering the diagnosis of a case of non-resolving pneumonia, in the context of Bangladesh, it is not surprising that as clinicians we rather prefer to consider pulmonary tuberculosis as the first differential, while keeping the others in mind while the diagnosis of malignancy as the least likely differential diagnosis.

Here we report a case of a 35 year old lady presenting with clinical features mimicking pneumonia who was ultimately diagnosed with large cell carcinoma.

\section{Case Report:}

A 35 year old housewife was admitted with the complaints of dry cough for two and half months, left sided chest pain for same duration and fever for two months. Fever was documented with the highest recorded temperature being $103^{\circ} \mathrm{F}$ without any alteration of appetite or significant change of body weight. She has no past history smoking, or TB. Her clinical examination revealed preference to right lateral position on decubitus. Her respiratory system examination revealed features of left sided pleural effusion. Her blood tests revealed $\mathrm{Hb}-10.2 \mathrm{gm} / \mathrm{dl}$, TC $-15500 / \mathrm{cumm}, \mathrm{DC}-\mathrm{N}$ $58 \%, \mathrm{~L}-32 \%, \mathrm{ESR}-140 \mathrm{~mm}$ in $1^{\text {st }}$ hour. CXR (P/A) \& left lateral view showed features of consolidation with left sided pleural effusion (Fig.-1).

Pleural fluid was haemorrhagic in naked eye appearance, Chemical and cytological analysis showed Protein - $5.9 \mathrm{gm} /$ dl, Cell count-N- 70\%, L-30\%, RBC-1552/cmm.Gram stain and AFB Stain of pleural fluid revealed no organism. Pleural fluid ADA and malignant cells could not be done due to insufficient amount fluid. CT of Chest with contrast revealed a mass lesion in left lower lobe of left lung with contrast enhancement (Fig -2). FNAC from the lesion was compatible with large Cell undifferentiated carcinoma (Fig.- 3,4).

1. Post-graduate trainee, Department of Medicine, Dhaka Medical College

2. Assistant Professor, Department of Medicine, Dhaka Medical College.

3. FCPS (Medicine) Course student, Dhaka Medical College

4. Professor, Department of Medicine, Dhaka Medical College

5. Assistant Registrar, Department of Medicine, Dhaka Medical College

6. Consultant, Medicine.Shaheed khalek-Ibrahim general hospital, National Healthcare Network, Wari

Correspondence: Dr. Mohammad Ashik Imran Khan, Post Graduate Trainee, Dhaka Medical College Hospital, Dhaka. E mail: ashikmrn@yahoo.com 

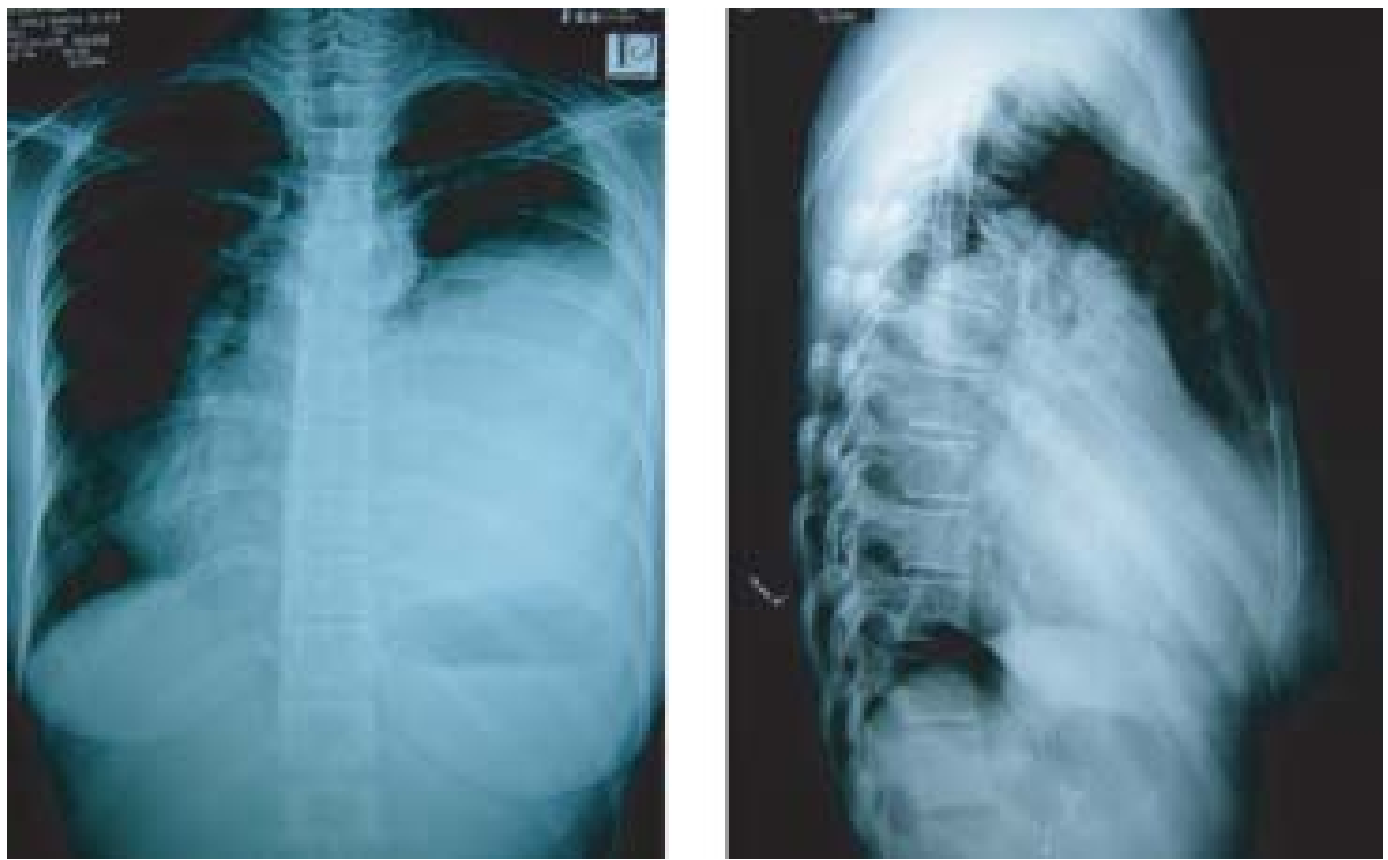

Fig-1. Showing a dense homogenous opacity occupying left mid to lower zone (P/A, \& Left lateral View; a, b respectively)

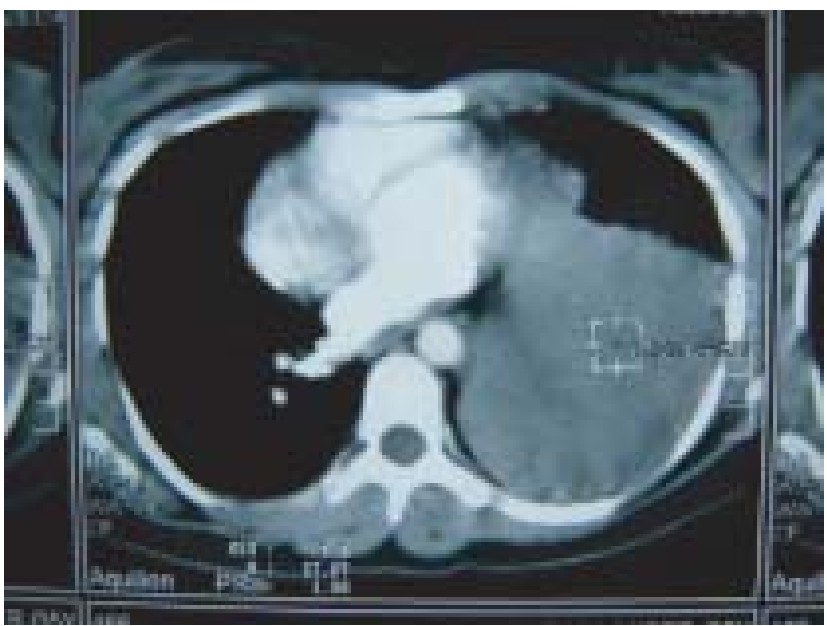

Fig.-2: Showing a mass lesion of left lower lobe with contrast enhancement

\section{Discussion:}

Bronchogenic carcinoma has varied presentation. Uncommonly it may present mimicking pneumonia which may mask the original disease and thus delay the diagnosis. But while considering the differential of a young individual presenting with cough, fever, chest pain, the differential of a malignancy being the cause is probably at the bottom of the list of the ones considered. Our patient presented with typical features of community acquired pneumonia. But her failure to respond various antibiotics resulted in consideration of

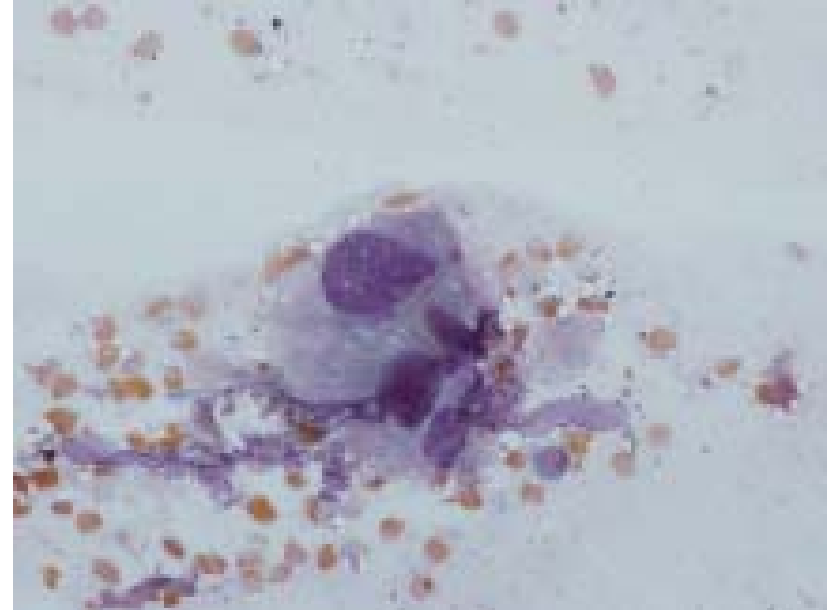

Fig.-3: Showing scanty cellular material containing a few malignant cell tumour cells in the background of tumour diathesis.

other diagnosis. Non-resolving pneumonia has been described as a clinical syndrome where focal infiltrates begin with some clinical association of acute pulmonary infection (fever, productive cough, dyspnoea) and despite at least 10 days of antibiotic therapy patient do not improve or worsen as indicated by clinically or by failure of radiographic opacities to resolve within 12 weeks of the onset of pneumonia. ${ }^{5}$ Slow resolution has been defined as the persistence of radiographic abnormalities for more than 1 month in a clinically improved patient. Approximately $90 \%$ 
of patients under 50 years show radiographic resolution by 4 weeks, whereas only $30 \%$ of patients older than 50 improve. ${ }^{6}$

Normal resolution of pneumonia is variable and depends on the causative agent, severity of disease at presentation and host factors. Approach to the evaluation of a nonresolving pneumonia should begin with meticulous assessment for risk factors that may contribute to delayed resolution. Specifically, the patients age and co morbidities, the severity of the pneumonia and the specific pathogen if identified as different pathogens have different rates of resolution. Resolution may be considered on clinical grounds (defervescence, resolution of leukocytosis) as well as radiographically. If the rate of resolution does not appear appropriate, it is important to revisit the history and assess for indications of unusual pathogens and noninfectious agents (careful assessment of social history, travel, exposures and risk factors for atypical and non-infectious causes). A chest CT and laboratory evaluations (serologies, sputum samples, antigen testing) is the next step in evaluation. If these studies are unrevealing, bronchoscopy is another option. Bronchoscopy may be considered in young non-smoking, immunocompetent young patients with prolonged multilobar disease. Bronchoscopy may identify organisms that are not responding to initial antibiotic regimen, but its affect on the disease outcome is not clear. The limitations of bronchoscopy include its late availability of information, simpler methods such as tracheal aspiration culture - that can provide information in a simpler, less invasive and more expedient manner and repeat testing usually isolates highly resistant organism that would not be eliminated by changes in antibiotic therapy and ultimately will not influence the further action. 7,8

In patients with nonresolving pneumonia, list of alternate diagnosis is a long one. Among the ones to be considered are tuberculosis, fungal pneumonia, nocardia and actinomycosis, neoplastic disorders of bronchogenic carcinoma, lymphoma, sarcoidosis, and bronchoalveolar carcinoma. Inflammatory disorders consisting of bronchiolitis obliterans organizing pneumonia, eosinophilic pneumonias, systemic vasculitis, and drug-induced lung diseases constitute a significant proportion. ${ }^{9}$ Bronchiolitis obliterans organizing pneumonia presents radiographically as a peripheral, patchy alveolar or air-space process and could be indistinguishable from bacterial pneumonia. Finally, pulmonary embolism and infarction may mimic pneumonia in up to $30 \%$ of the cases. ${ }^{10}$ Treatment failure of a presumed pneumonia should be further investigated by highresolution CT scan. ${ }^{11}$
Unfortunately our patients initial investigations failed to point towards a diagnosis. Her blood picture showed leucocytosis. Though acute infection mostly present with such blood picture but surprisingly malignant tumors are often found to be associated with leukocytosis as well; in fact, leukocytosis has been observed in $89 \%$ of patients with large cell carcinoma, and it is believed to be a characteristic symptom of this type of tumor. ${ }^{12}$

Presentation of lung cancer in such young age is without any risk factor not very common. In Bangladesh, analysis of a single center experience reveal that almost $86 \%$ of the patients of lung cancer are male and most belonging to older age group whereas onle $4 \%$ patients suffer from large cell carcinoma. ${ }^{13}$ Regarding presentation on lung cancer in the young, several case-control studies on young subjects have revealed a high proportion of female patients being affected. Adenocarcinoma is most commonly the culprit but most of them showing an association between lung cancer and smoking. ${ }^{14-16}$ Results of segregation analyses indicate that the inheritance of a rare major autosomal gene results in an earlier age of onset of lung cancer. Many epidemiologic and clinical studies have indicated familial aggregation of lung cancer as well. There has been a threefold increase in risk of lung cancer in subjects younger than 46 years if relatives were also affected by lung cancer with no elevated risk in older people. ${ }^{17-19}$ The impact of passive smoking on a partner is enormous as it has been demonstrated that a nonsmoker whose spouse is a smoker is at increased risk of developing lung cancer. ${ }^{20}$ But as the patients husband was living away from her and she did not have a history of exposure to smoke by passive means. Without any family history, no risk factor was found in this patient. She was transferred to department of oncology for further treatment.

In conclusion, it can be said that there has been a shift with more women being affected with lung cancer but no single absolute risk factors that contribute to an early onset of lung cancer has been found. This needs further work to improve outcome of lung cancer in these patients.

\section{Acknowledgement:}

Professor (Dr.) Mohammad Golam Mostafa

\section{Conflict of interest : None}

\section{References:}

1. Zamboni M. Epidemiologia do câncer do pulmão. J Pneumol. 2002;28(1):41-7

2. Castro MS, Vieira VA, Assunção RM. Padrões espaçotemporais da mortalidade por câncer de pulmão no Sul do Brasil. Rev Bras Epidemiol. 2004;7(2):131-43 
3. Instituto Nacional de Câncer - INCA [homepage on the Internet]. Brasília: Ministério da Saúde. [cited 2007 Nov 27] Estimativa/2008. Incidência de Câncer no Brasil. Available from: http://www.inca.gov.br/estimativa/2008

4. Blot WJ, McLaughlin JK. Are women more susceptible to lung cancer? J Natl Cancer Inst. 2004; 96(11):812-3

5. Low DE. Progressive Progressive and nonresolving pneumonia. Curr Opin Pulm Med. 2005 ; 11(3):247-52

6. Johnson JL. Slowly resolving and nonresolving pneumonia: questions to ask when response is delayed. Postgrad Med 2000; 108:115-122

7. Menendez R. Evaluation of nonresolving and progressive pneumonia. Semin Respir Infect. 2003 ;18(2):103-11

8. Niederman, MS. Bronchoscopy in nonresolving nosocomial pneumonia.Chest. 2000 ;117(4 Suppl 2):212S-218S.)

9. Calenoff TW, Berlin B. Bacterial or nonbacterial pneumonia: accuracy of radiographic diagnosis. Radiology 1977; 124:607612

10. He H, Stein MW, Zalta B, Haramati LB. Pulmonary infarction: spectrum of findings on multidetector helical CT. J Thorac Imaging 2006; 21:1-7

11. Tanaka N, Matsumoto T, Kuramitsu T, et al. High-resolution CT findings in community-acquired pneumonia. J Comput Assist Tomog 1996; 20:600-608.
12. Ascensao JL, Oken MM, Ewing SL, et al. Leukocytosis and large cell lung cancer frequent association. Cancer 1987;60:903-5

13. Department of Cancer Epidemiology, National Institute of Cancer Research \& Hospital. Annual Report 2005. Dhaka, Bangladesh 2005:1-17

14. Jubelirer SJ, Wilson RA. Lung cancer in patients younger than 40 years of age. Cancer 1991;67:1436-8

15. Green LS, Fortoul TI, Ponciano G, et al. Bronchogenic cancer in patients under 40 years old. The experience of a Latin American country. Chest 1993;104:1477-81

16. Sellers TA, Bailey-Wilson JE, Elston RC, et al. Evidence for mendelia inheritance in the pathogenesis of lung cancer. $\mathrm{J}$ Natl Cancer Inst 1990;82:1272-9

17. Risk Factors for Lung Cancer in Young Adults Michaela Kreuzer, Lothar Kreienbrock, Michael Gerken,et al Am J Epidemiol. Vol. 147, No. 11; 1028-1037

18. Steven J. Jubelirer, Robert A. Wilson. Lung Cancer in Patients YoungerThan 40 Years of Age Cancer 67:1436-1438, 1991

19. Takagi H, Sekino S, Kato T, Matsuno Y, Umemoto T. Revisiting evidence on lung cancer and passive smoking: adjustment for publication bias by means of "trim and fill" algorithm. Lung Cancer. 2006; 51(2):245-6 